\title{
Analysis on the Current Status and Existing Problems of Overseas Engineering Insurance
}

\author{
Yi Liang ${ }^{1,2,3,{ }^{*}}$ Hanping Zhao ${ }^{1,2}$
}

\author{
${ }^{1}$ Key Laboratory of Environmental Change and Natural Disaster, Ministry of Education, Beijing Normal University, \\ Beijing 100875, China; \\ ${ }^{2}$ Academy of Disaster Reduction and Emergency Management, Ministry of Emergency Management \& Ministry of \\ Education, the Peoples' Republic of China, Beijing 100875, China \\ ${ }^{3}$ PICC Property and Casualty Company Limited Beijing Branch, Beijing 100010, China \\ *Corresponding author. Email: yliang1990@126.com
}

\begin{abstract}
The "Belt and Road" initiative takes policy communication, facility connectivity, unimpeded trade, financial integration, and people-to-people bonds as its core, to create a community of interests, a community of destiny, and a community of mutual benefit and responsibility for mutual political trust, economic integration, and cultural inclusiveness. It has become a global mutually beneficial and win-win cooperation. China has made considerable progress in the process of integrating into the world economy and has become a major trading country with global influence. However, my country's ability to prevent overseas risks in general is still lagging, and is not commensurate with its status as a major trading country. In particular, the "Belt and Road" strategic radiation area involves a large number of countries, a large population, and complex and changeable geopolitical and economic relations. In the process of "going out", there are more political risks, economic risks, legal risks, default risks, man-made accidents and natural disaster risks. The insurance industry is a special industry that manages and transfers risks. As a kind of "community of destiny" with a long history, insurance organization, as a mature tool for risk prevention in international economic affairs, its own characteristics determine the service area of the insurance industry. The construction of the "Belt and Road" has natural advantages and should play a greater role closely following the national strategy, providing comprehensive risk protection and services for the "Belt and Road" cross-border cooperation, and alleviating the worries of enterprises "going out". To provide strong support for accelerating the construction of the "Belt and Road" and escort China's overseas interests.
\end{abstract}

Keywords: Overseas engineering project, The "Belt and Road" initiative, Engineering insurance, Risk management

\section{中国海外工程保险经营现状及存在问题剖析}

梁神 $1,2,3$ * 赵晗萍 1,2

\author{
${ }^{1}$ 北京师范大学，环境演变与自然灾害教育部重点实验室，北京 100875, 中国 \\ 2 应急管理部/教育部减灾与应急管理研究院, 北京 100875 , 中国 \\ ${ }^{3}$ 中国人民财产保险股份有限公司北京市分公司，北京 100010，中国 \\ *通讯作者.电子邮箱: yliang1990@126.com
}

摘要

“一带一路” 倡议以政策沟通、设施联通、贸易畅通、资金融通、民心相通为核心，打造政治互信、经济融 合、文化包容的利益共同体、命运共同体和责任共同体，已成为全球互利共赢的合作新平台，中国因此而在 融入世界经济的进程中取得了长足的进步，成为具有全球影响力的贸易大国。然而，我国海外风险防范的能 力总体依然滞后，与贸易大国的地位并不相称，特别是 “一带一路” 战略辐射区域涉及国别众多，人口数量 
庞大，地缘政治、经济关系复杂多变，我国企业 “走出去” 过程中面临着较多的政治风险、经济风险、法律 风险、违约风险、人为事故与自然灾害风险。保险行业作为管理风险和转移风险的特殊行业, 保险组织作为 一种历史悠久的 “命运共同体” ，保险机制作为国际经济事务中通行的风险防范的成熟工具，其自身特点决 定了保险行业服务 “一带一路” 建设具有天然优势，理应在 “一带一路” 建设中发挥更大作用，紧跟国家战 略, 为 “一带一路” 跨境合作提供全面的风险保障与服务, 减轻企业 “走出去” 的后顾之忧, 为加快推进 “一带一路”建设提供有力支撑，为中国海外利益保驾护航。

关键字: 海外工程，一带一路，工程保险，风险管理.

\section{1. 海外工程经营现状}

海外工程是国际工程市场的一个重要组成部分, 强有力的带动了国际经济合作, 合作涉及到政治、 经济、资金、物资、技术、管理以及人力等多个方 面, 有利于各个国家充分发挥组织优势, 有效节约 成本, 快速学习优秀经验。目前海外工程项目多集 中于 “一带一路” 沿线地区, “一带一路” 沿线包 括东盟、南亚、西亚、中亚、北美和欧洲等 65 个国 家, 沿线国家经济总量约占世界经济总量的 $31 \%{ }^{[1]}$ 。 本文将海外工程研究重点集中于 “一带一路” 沿线 地区中国承包商参建的工程项目, 项目类型包括不 限于道路工程、桥梁工程、轨道交通工程、水电站 工程、房屋工程、电网工程、电厂工程等。

根据商务部公开数据显示, 仅 2020 年 1-9 月, 我国企业在 “一带一路” 沿线对 57 个国家非金融类 直接投资 910.3 亿元人民币, 同比增长 $32.3 \%$ （折合 130.2 亿美元, 同比增长 $29.7 \%$ ）, 占同期总额的 $16.5 \%$, 较上年同期提升 4.1 个百分点, 主要投向新 加坡、印尼、老挝、越南、柬埔寨、马来西亚、泰 国、哈萨克斯坦、阿联酋和缅甸等国家。对外承包 工程方面, 我国企业在 “一带一路” 沿线的 61 个国 家新签对外承包工程项目合同 3478 份, 新签合同额 5852.8 亿元人民币, 占同期我国对外承包工程新签 合同额的 55.7\%, 同比下降 1.6\%（折合 837.1 亿美 元，同比下降 3.6\%）; 完成营业额 3714.7 亿元人民 币，占同期总额的 58.2\%，同比下降 3\%（折合 531.3 亿美元，同比下降 4.9\%）[2]。美国《工程新闻纪录》

(ENR) 最新发布的 2019 年 “全球最大 250 家国际 承包商” 榜单中, 75 家中国企业入围, 较上年增加 6 家, 数量再创历史新高, 蝉联各国榜首。从各国上 榜企业国际营业总额来看, 中国企业在 2018 年实现 国际营业额 1189.67 亿美元, 同比增长 $4.3 \%$, 占 250 家上榜企业国际营业总额的 $24.4 \%$, 较上年提升 0.7 个百分点。3 家中国企业进入榜单前 10 强, 共有 10 家中国企业进入榜单 50 强 ${ }^{[3]}$ 。
“一带一路”两头分别是活跃的东亚经济圈和 发达的欧洲经济圈, 由于覆盖区域广阔、包含的国 家众多、经济发展水平各异，使得沿线各国基础建 设水平区域差异明显。比如, 泰国目前只有约 4,000 多公里的铁路, 每小时运行速度只有 30-40 公里, 运 力比较低; 巴基斯坦有些工业城市每天只能供电 4-6 小时; 这就导致基础设施建设是 “一带一路” 倡议 的优先领域和基础环节, 只有沿线国家的基础设施 水平得到有效提高, 投资环境才能改善, 才会带动 沿线投资和贸易发展，因此以电厂、电网、桥梁、 道路等基础设施建设为主的对外承包工程项目是中 国企业走出去的主要工作领域。

机遇存在的同时必然伴随着挑战。一方面 “一 带一路” 沿线国家，尤其是中东等地区，由于宗教、 领土、恐怖主义问题使得地区冲突不断, 比如中亚 阿富汗问题、南亚印巴克什米尔问题、西亚叙利亚 问题等。另一方面各国政治体制各异，有社会主义 国家，也有资本主义国家。有些国家政治不稳定， 政权更迭频繁, 例如马来西亚政府换届, 导致前期 已中标的东部铁路工程项目延缓开工, 或已开工又 进入停滞状态; 更加重要的是 “一带一路” 沿线国 家自然灾害易发、多发和频发, 灾害类型多样, 经 济水平低下导致抗灾能力弱, 严重威胁生命财产安 全、通道安全、投资安全, 制约经济社会发展。以 上这些都对 “一带一路” 沿线基础设施先行和投资 施工企业经营带来不确定性和风险。这些风险因素 不仅可能导致国际基础设施建设项目亏损、延期、 停滞、失败, 还会影响我国驻外的工程相关人员人 身财产安全 ${ }^{[4]}$ 。

\section{2. 海外工程保险经营现状}

2012 年-2018 年我国工程险市场发展迅猛, 特别 是 2016年以后年均增速超过 $10 \%$, 截止 2018 年末我 国工程险保费收入为 120.79 亿（行业内部数据）; 虽然整体发展势头良好, 但是近年来市场整体盈利 水平偏差, 自 2014 年以来连年亏损, 整体亏损金额 为 19.14 亿元, 整体市场竞争呈白热化趋势。基于国 
内某大型财产保险公司 2012 年-2018 年工程保险经 营数据, 笔者对此统计时间段内的海外工程保险业 务的承保数据进行了分析, 希望通过对历史承保项 目进行多维度分析, 发现工程保险海外业务历史承 保过程中的问题，了解行业整体发展趋势。

\section{1 工程保险海外业务保单数量及保费收入情 况}

从保单数量角度来看, 国内业务和海外业务保 单数量均稳步增长, 其中国内业务增长趋势明显, 特别是自 2016 年以来, 连续快速增长, 截止 2018 年 底, 国内保单数量已突破 3 万笔。从保单数量来看, 海外业务保单数量占比较低, 出单工作量相对较少。

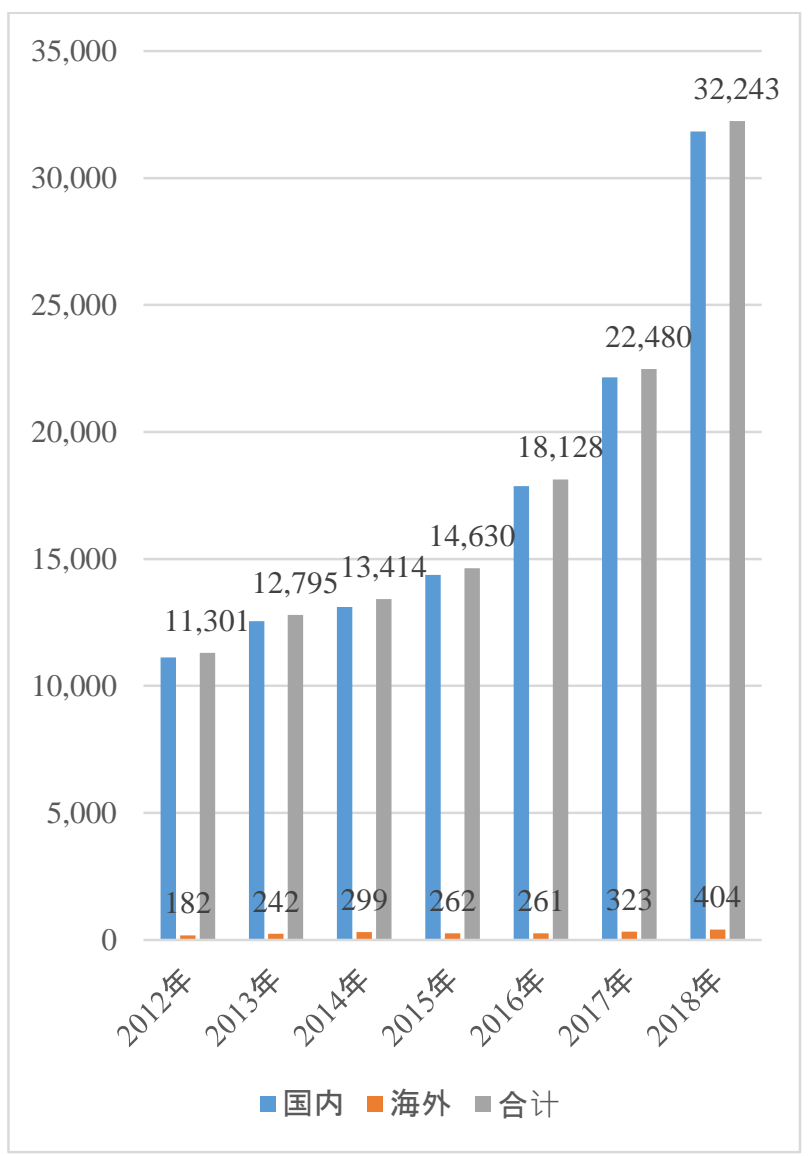

图 12012 年-2018 年国内、海外业务保单数量情况 (单位: 个)

\section{2 工程保险海外业务 2012 年2018 年国内、 海外业务保费收入、增速及占比}

2012 年至 2018 年国内工程险业务逐年稳步增长, 而海外业务波动性较大。从业务占比来看, 海外工 程险业务约占工程保险整体保费收入 9.57\%左右。

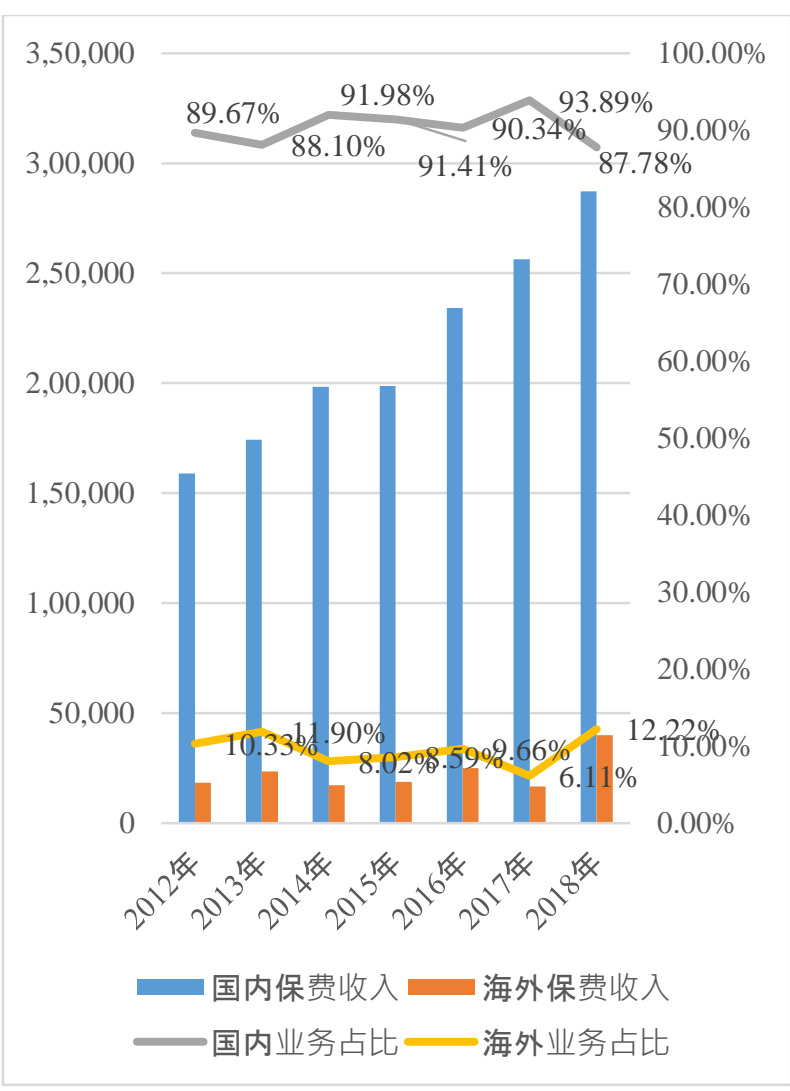

图 22012 年-2018 年国内、海外业务保费收入、增 速及占比（单位: 万元）

从工程类别角度来说, 海外业务主要依靠道路 类、铁路、水利水电项目类、房屋楼宇类、火电站 类、堤坝类、公共设施、治金工业类、陆地管线工 程及供水工程, 保费收入超过 5000 万。从平均费率 角度对比来看, 国内和海外业务费率均有不同程度 的下降, 但是海外业务的费率下降趋势更为明显。 从国内和海外平均费率来看, 地铁类、轻轨类、道 路类、铁路类、公共设施类项目费率海外平均费率 已经低于国内平均费率, 特别是地铁类业务, 海外 业务的费率水平远低于国内费率水平; 道路、铁路 类业务无论是国内还是海外保费规模均较大, 但是 整体赔付情况较差, 而海外业务费率低于国内水平 可能对工程保险整体盈利带来比较大的影响。

\section{3. 保险业服务海外工程优势}

根据瑞士再研究院的统计，2018 年全球因自然 灾害和人为灾难导致的经济损失高达 1650 亿美元。 其中具有保险保障的部分仅 850 亿美元，仍有 $50 \%$ 的损失由政府和大众承担，风险敞口之大触目惊心 [5]。保险业既是金融业的重要组成部分，又是管理 风险的特殊行业, 其自身特点决定了保险行业服务 共建 “一带一路” 具有天然优势, 能够为 “一带一 路” 跨境合作提供全面高质量的风险保障与服务。 具体来说, 保险业可以从政策沟通、设施联通、贸 易畅通、资金融通、民心相通这五大共建重点，充 分发挥行业优势，贡献行业智慧。 
首先是政策沟通。企业 “走出去”, 离不开保 险行业的保驾护航。“一带一路” 沿线有很多不发 达国家和地区，有着较高的政治风险、经济风险、 社会风险和技术风险, 中国银行保险监管部门与沿 线国家的政府部门开展的高层次合作, 非常有利于 企业利用保险行业的风险管理团队和技术来化解各 行各业参与 “一带一路” 建设中所面临的各种风险。 当 “一带一路” 建设中风险损失出现时, 保险公司 的参与可以及时进行国际化的经济补偿, 缓解国家 之间、劳资之间、企业之间的各种矛盾, 保证建设 的稳定性和持续性。

2015 年以来, 中国保险监管部门与“一带一路” 沿线国家签署了多个合作协议, 比如, 原中国保险 监督管理委员会与欧洲保险和职业养老金管理局谅 解备忘录; 中俄保险业合作发展行动计划; 中俄保 险监管合作谅解备忘录; 中美保险监管合作谅解备 忘录。国家监管层面的保险合作成为中国保险公司 参与“一带一路”建设和进行相应海外布局的坚实基 础。

其次是设施联通。设施联通是 “一带一路” 建 设的核心工作之一。大量的基础设施建设时刻面临 着人身、财产、责任和信用风险, 而作为专业的风 险管理机构, 在工程建设中, 保险公司的风险管理 团队、技术和流程, 非常有利于将大大小小的风险 点进行事先排查、事中管理和事后补偿, 将众多的 风险化解于无形, 以最小的成本最大程度地保护沿 线国家和建设企业人民生命财产的安全。

第三是贸易畅通。当今的世界经济, 没有保险 的国际贸易是不可思议的。无论是国际货物运输保 险, 还是信用保险, 保险在国际贸易中的作用被证 明是无可替代的。近些年来, 中国的航运业发展迅 速。继 2012 年成为世界第一造船大国后, 2013 年中 国又成为世界第一货物贸易大国; 全球货物吞吐量 最大的十个港口有七个在中国, 但中国航运保险的 发展还未能完全追上中国航运事业的脚步。积极参 与保障 “一带一路” 的贸易畅通, 既是中国保险业 的职责, 也是中国保险业能够奋起直追, 匹配国际 贸易大国地位的良机。

第四是资金融通。在 “一带一路” 战略中, 银 行业在资金融通方面占有主导地位，但其所承担的 风险也不容忽视。利用保险业的风险管理优势, 与 银行业协同作战, 事先化解银行业所面临的各种风 险, 原本就是保险业应有的长项与应尽之责。同时, 保险业资金融通的作用也越来越强大。2018 年末, 中国保险业的资金余额达到 16.40 万亿元, 而且随着 保险费收入的迅速增长, 保险公司可以运用的资金 还会大幅增加, 在 “资产荒” 的背景下, 保险公司 都在寻求既能保证资金安全性, 又能保证资金收益 性和流动性的保险资金运用渠道。而 “一带一路” 沿线国家的沿线资源丰富，但是资本市场的发展水
平并不高，因此拓展资金融通渠道，将保险资金引 流进去的工作就显得特别关键。

第五是民心相通。“一带一路”建设不但是经 济上的国际合作，也是中国文化与其他文化的交流。 中国保险业通过支持 “一带一路” 建设走出国门, 可以将中国文化中的居安思危、未雨绸缪、防患于 未然等风险意识和防灾防损意识传播出去, 造福其 他国家和地区的人民; 可以通过保险的风险分散和 经济补偿职能, 以市场化的手段, 保障沿线居民的 生产生活, 带动沿线发展中国家保险业的发展, 以 促进沿线国家社会的和谐与稳定。保险业 “通民心” 作用的发挥可能会比较缓慢, 但却最为持久。

由此可见，在 “一带一路” 建设中，保险可以 成为很好的政策手段和政策工具，以其特有的商业 属性, 助力于国家 “一带一路” 战略的实现。

\section{4. 保险业服务海外工程现状}

自共建 “一带一路” 倡议提出以来，依靠有效 的双多边机制和区域合作平台，贸易畅通、资金融 通不断深化。但在各国联通程度和依赖程度前所未 有地加强的同时，各国面临的风险挑战也愈发严峻， 地域差异性明显, 风险复杂多样, 政治风险、社会 风险、法律风险、违约风险和自然灾害风险较大。 保险是现代社会风险管理的基本手段，也是国际经 济事务中通行的风险防范成熟机制, 理应在 “一带 一路”建设中发挥更大作用。

目前, 我国保险公司重点在基础建设、贸易畅 通、国际产能合作、民心互通等方面为服务 “一带 一路”高质量发展做出了突出贡献。

在对接 “一带一路” 基础设施建设方面，我国 保险公司积极为诸多项目建设提供了风险保障, 包 括有国际影响力的海外工程项目, 如雅万高铁、中 老铁路、肯尼亚蒙内铁路、老挝南欧江水电站、巴 基斯坦卡西姆港燃煤电站等项目，涉及到的服务或 产品有工程险、企财险、工程相关的境外的责任险 以及工程相关的货运险、中资机构的安保服务等。

在促进 “一带一路” 沿线国家贸易畅通方面, 保险公司提供了包括进出口贸易货运险、远洋船舶 险以及短期出口信用险、出口产责险在内的多种保 险服务, 主要服务于 “走出去” 企业海外的商贸活 动。

在促进国际产能合作方面, 我国保险公司为核 能、航空航天、石油化工等项目的特殊风险提供保 险解决方案。例如, 我国险企在核能险方面参与承 保项目有巴基斯坦卡拉奇核电项目、英国欣克利角 核电项目等; 航天险方面主要为民航机队（全球第 一大机队）的联合保单，并对于海外的埃及二号卫 星、老挝亚太卫星等项目提供了保险保障, 这些项 目多为中国和海外的产能合作项目; 石油险方面, 中石油、中石化、青海油等中资能源企业在海外的 
60 余个国家的石油资产的保险保障基本上都有我国 险企的参与; 近年来我国险企还开展了首台套重大 技术装备保险的试点, 为装备制造企业 “走出去” 开拓海外市场保驾护航。

在服务 “民心相通”工作方面，险企业对于境 外的工作人员、出境旅游人员、商务人员以及海外 留学生，提供了医疗保险、健康保险、雇主责任险、 海外防御保险等。

另外，部分中国保险企业还通过国际合作的方 式, 建立全球化服务网络, 为 “走出去” 的中国企 业和公民提供全球化、专业化的本地服务。一方面， 帮助会员企业在线寻找海外园区; 组织会员企业海 外考察; 帮助会员企业与各合作方进行资源整合、 商业（项目）对接; 引导会员企业, 将自身优势与 投资目的地实现高效配置和优质组合。还可以在全 球范围内为中国出境公民提供全天候的救援和救助 服务, 提供更加高效和个性化的服务。

\section{5. 保险业服务海外工程存在的问题}

在 “一带一路” 建设过程中保险机构服务各类 企业 “走出去” 取得一定成绩的同时, 也存在诸多 突出的问题, 亟需按照党中央高质量发展的要求, 提升保险业服务“一带一路”国家战略的能力和质量。

\section{1 保险业海外风险管理能力严重不足}

保险业海外风险管理能力严重不足, 尚不能为 “走出去” 参与 “一带一路” 建设的企业提供强大 的风险识别、评估、处置与优化等一系列的风险管 理服务, 在目前我国尚没有任何一家保险公司具备 足够的国际化风险管理能力的情况下, 我国保险业 风险管理服务的综合竞争力将在相当长的时间内都 难以较好地担当为 “一带一路” 企业保驾护航的重 任, 反而是各家保险公司在国际市场竞争中彼此掣 肘, 陷入价格竞争泥潭的倾向愈发明显。

\section{2 海外经营管理基础薄弱, 属地服务水平低}

中国保险企业国际化发展还处于较为初级的阶 段, 海外分支机构较少, 自主性全球化服务网络尚 未建立。险企往往需要在相对成熟的条件下才会考 虑设立海外分支机构, 例如分支机构要能够有效运 营、可持续经营, 能够保证其承保稳健、财务稳健、 投资稳健, 避免形成僵尸企业等等, 这些现实需要 往往会使险企在海外扩张时保持审慎态度。

险企海外经营管理基础薄弱, 直接影响了其属 地服务能力。一方面，在海外经营保险业务涉及到 当地的监管问题，大多数地区的保险业务只能通过 当地的机构出单, 除非在当地设立机构作为直保公 司出单, 或者得到当地政府的豁免, 但得到豁免往 往比较困难, 特别是当一国法律或项目业主要求在 当地为项目投保的情况下, 往往会造成业务流失的
结果。另一方面, 一旦承保的项目出险, 险企难以 做到迅速响应，查勘、定损、救援、理赔等一系列 工作都较为滞后，属地服务水平较低。目前，中国 险企更多是以派驻工作组、战略合作伙伴、保险经 纪公司、海外分公司（这种情况较少，如大地保险 公司可以通过中再新加坡分公司、桥社新加坡公司 以及桥社澳大利亚 SLE 公司等经营海外业务) 等多 种模式为 “走出去” 企业提供保险服务。中国险企 在 “夹缝” 中服务 “一带一路” 战略的现实情况亟 需得以改善。

\section{3 缺乏海外业务经营经验}

保险公司在开拓海外业务方面缺乏相应经验, 从项目试点到取得相应成果, 不仅需要时间, 也需 要和海外企业进行政策、战略等方面的协调。险企 对于海外的法律问题、宗教问题、民风民俗问题等 了解不够具体全面, 在一定程度上加大了项目实施 的风险, 提高了成本。

\section{4 信息共享水平低}

险企经营海外业务, 信息不对称问题较为严重, 面临着诸如政治制度风险、经济制度风险、文化冲 突等风险, 经营海外业务常常存在各种隐患。险企 常规的做法是通过自主研究、购买相关信息与服务、 与境外国家的公司多方联系等方式获取必要信息, 各自为战, 成本高、效率低, 大大制约了险企服务 “一带一路”战略的前进步伐。

\section{5 业务统计口径影响险企经营海外业务的积 极性}

海外直保方式受限的情况下，保险公司往往选 择 “曲线救国”，以再保人的身份参与海外业务, 但获得的保费只能以再保险的口径进行统计, 而中 国原保险保费和再保险保费分开统计的制度，直接 会影响保险公司的最终业绩水平, 这一定程度上降 低了保险公司经营海外业务的积极性。

\section{6 缺乏复合型人才}

保险公司经营海外业务过程中，往往需要具备 一定海外工作经验和专业知识技能的综合性人才, 只有充分了解被服务国家的相关政治制度、经济制 度、法律政策、文化习俗等, 保险公司才能更好地 适应国外市场环境, 更好地经营海外业务、提供海 外服务。目前从整个保险业来看, 国际化人才仍然 较为稀缺。

\section{7 产品创新不足}

在产品设计方面, 现存产品未能充分满足企业 走出去的保障需求，不能充分覆盖企业面临的风险 
保障缺口，如针对延期开工(DSU)、政治暴力 (PV)、 疾病意外、政治风险等各种新型风险，国内保险行 业自主开发的产品相对滞后, 直保产品和中文条款 开发落后于市场需求。

\section{8 外汇风险影响较大}

保险企业在经营国际业务过程中，常常受到外 汇风险的困扰。在境外当地签订原保单或者收取原 保费支付再保费时，客户或者机构会要求使用当地 币种，保险公司境外结算货币多使用美元，而某些 国家当地币种比较小众, 经营长期责任的保单业务 时, 前期承保、后期理赔以及保费的分期缴付中, 产生的结算风险与汇兑风险均难以规避。另外, 还 存在某些国家的币种特殊, 中国银行也无法及时提 供帮助的情况, 导致保费数量无法计算, 保费无法 收取。

\section{6. 小结}

总体而言, 在服务 “一带一路” 国家战略中, 国内保险公司尚未形成合力, 且普遍缺乏海外服务 经验和稳定的保险支持, 对于中国海外利益保险的 供给相对滞后, 造成了较严重的中国海外利益保费 外流，一些涉及国家战略和国家核心利益的保险项 目由外资保险公司参与甚至主导, 对国家核心利益 造成潜在威胁, 保险自主权亟待加强。目前, 国内 保险公司对于中国海外利益采取国内统保国外出单 模式, 对海外利益的保险服务能力有限, 而且存在 一定灰色地带。对东道国监管未给予充分尊重, 影 响中国保险业的国际形象, 一旦发生重大赔案件, 容易引发国际纠纷, 造成比较恶劣的国际影响。

可以预见，随着 “一带一路” 倡议的持续推进, 中国海外利益仍将持续增加，相应的保险发展空间 也在不断扩大。但在服务 “一带一路” 中国海外利 益的保障工作中, 还存在现有保障覆盖不足, 缺乏 针对性保障产品, 境外出单存在挑战, 境外理赔服 务滞后, 尚未建立风险评估体系, 特殊风险再保险 支持不足等情况或问题。因此, 不论是基于中国保 险业行业发展的需要, 还是上升到更高一个层面的 国家战略，中国保险业都必须尽快搭建并健全服务 国内保险业的海外网络平台, 实现紧跟企业 “走出 去” 步伐的海外风险保障服务支持, 更加切实有效 地为 “一带一路” 保驾护航。建议监管部门从顶层 设计的角度出发, 把保险服务, 特别是风险管理服 务作为一项制度保障, 纳入国家 “一带一路” 战略 的总体布局之中。这对于国内保险公司争取更多保 费和提高国际业务能力, 对于保险业捍卫主权和更 好地服务 “一带一路” 建设, 都具有重要的意义。

\section{参考文献}

[1] 北京师范大学新兴市场研究院, “一带一路” 研 究院. 《“一带一路”沿线国家经济社会发展报 告》[J]. 经济研究参考,2017,03:1-50。

[2]http://fec.mofcom.gov.cn/article/fwydyl/tjsj/202010/ 20201003011295.shtml

[3] http://www.sohu.com/a/335551186_444154

[4] 王欣杰. “一带一路” 背景下莫喀高铁项目建设 阶段承包商风险管理实证研究 [D].西南交通大 学,2017.

[5] https://www.swissre.com/institute/research/sigmaresearch/sigma-2019-02.html 